\title{
A tribute to John B. Fountain
}

\section{Victoria A. R. Gould ${ }^{1}$. Mark V. Lawson ${ }^{2}$}

Received: 29 May 2019 / Accepted: 29 May 2019 / Published online: 17 June 2019

(๑) The Author(s) 2019

\section{Abstract}

John Fountain has had a remarkably successful career in semigroup theory, as a researcher, as a Ph.D. supervisor and as a mentor. Here two of his students reflect on John's mathematical life and his influence on their careers and those of others.

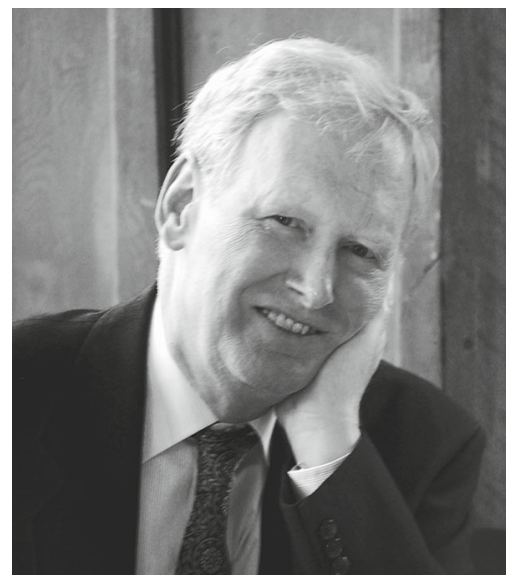

John B. Fountain

\section{Communicated by László Márki.}

$\bowtie$ Victoria A. R. Gould

victoria.gould@york.ac.uk

Mark V. Lawson

m.v.lawson@hw.ac.uk

1 Department of Mathematics, University of York, Heslington, York YO10 5DD, UK

2 Department of Mathematics and The Maxwell Institute for Mathematical Sciences, Heriot-Watt University, Riccarton, Edinburgh EH14 4AS, UK 


\section{Introduction}

John Fountain's impact upon algebraic semigroup theory has been both long-lasting and deep. It is impossible to capture all of his influences in a short article. They range from work in the early years on acts over monoids, through a number of strategies John developed to understand and study semigroups that need not be regular-semigroups of quotients, abundant semigroups and the like, covering theorems and idempotent generated semigroups - to more recent work on reflection monoids. These strands are interconnected mathematically, and intertwined with the story of John's work as supervisor and collaborator. It is the human development of his work that we have focused on here, informed by our own experiences of John and his own mathematical reminiscences. The readers can check his latest statistics themselves: at the point of writing John has 2434 citations across 70 outputs, $21 \mathrm{Ph}$.D. students and at least 40 mathematical descendants.

\section{The accidental semigrouper}

John B. Fountain was born on 16th October 1941 in Yorkshire, England, where he has lived and worked all his life. John wrote his thesis at the University of Leeds on nilpotent rings, under the supervision of Eric Wallace, graduating in 1965. In the same year, John was appointed Assistant Lecturer in mathematics at the (then) new University of York where he worked until he retired, and is now a Professor Emeritus. Alfred Goldie, famous for characterising rings having a semisimple Artinian ring of quotients, was also at Leeds during the 1960s. As we will see, Goldie's work had a lasting influence on John.

The turning point in John's research came whilst browsing in the University library. He came across a book entitled simply 'Semigroups' [8], a collection of papers from a conference. Two of these kindled John's interest: one by John Rhodes [40] and the other by Douglas Munn [37]. Rhodes's work on the Krohn-Rhodes decomposition theorem was also described in an article by David du Feu entitled 'Machines' which appeared in the Warwick University mathematics students magazine Manifold (Issue 5, Autumn 1969). As a result, John bought Arbib's book 'Algebraic Theory of Machines, Languages, and Semigroups' [2] and his mathematical course was set.

In the summer of 1970, John was granted a sabbatical for the following year. Since both Douglas Munn and John Howie were at Stirling, he thought he would like to go there. At the ICM in Nice in 1970, John was introduced to Howie who said he would be happy to host John's sabbatical but that it would have to be in St Andrews, rather than Stirling, because he was starting his new post there. As a result, John moved with his family to Anstruther, a fishing village near St Andrews, for six months in 1971.

At that time, pursuing semigroup theory as a kind of non-additive analogue of ring theory was both the fashion and fruitful. Howie, knowing John's ring theory background and facility with modules, showed him some papers characterising monoids in terms of properties of the acts over them. Inspired by these, John worked on completely right injective semigroups and perfect semigroups, leading to his first two papers $[9,10]$ on semigroups, which are remarkable in their clever use of what our 
students call 'semigroup trickery'. The first [9] gives a complete characterisation of those monoids such that all their right acts are injective. A key in the proof is that $\mathcal{H}$ is a right congruence on such monoids; in showing this John made use of ideas in preprints of Tom Hall on the structure of orthodox and regular semigroups, brought to his attention by Howie. The second [10], together with J. R. Isbell's paper [27], completely describes those monoids such that every flat right act is projective.

\section{Victoria Gould}

My first direct experience of John was sitting in his undergraduate lectures on mathematical logic in the early 1980s. John's accuracy, calmness, unapologetic good style and uncompromising quality, was immensely appealing. He became my Ph.D. supervisor in 1982, and immediately set me to work on two themes: acts over monoids and semigroups of quotients. The first topic involved looking at weak injectivity properties of acts and this quickly led to ideas relating to axiomatisablity of classes of acts and finitary properties of monoids. The second became the subject of my eventual thesis. From Goldie's influence through to the sabbatical in St Andrews, when Howie remarked in passing that the Rees theorem was the semigroup analogue of the Artin-Wedderburn theorem for simple Artinian rings, John had been mulling for many years over how to tackle quotients for semigroups. The problem is completely 0 -simple semigroups are not monoids, and ring theory techniques and their analogues only work for monoids, inverting elements in the group of units. The key was found by John in the early 1980s, when collaborating with Mario Petrich, and that was to invert elements in any subgroup of a semigroup. This led to an analogue of Goldie's theorem [22], and then to a whole theory of semigroups of quotients, eventually indeed feeding back to ring theory to rings of quotients where the parent ring is not unital [20].

John's work on acts over monoids led to another wonderful direction, indeed to a whole school of semigroup theory. A monoid has the property that every principal one sided ideal is projective if and only if there is an idempotent in every $\mathcal{R}^{*}$-class and every $\mathcal{L}^{*}$-class. John called such semigroups having the latter property abundant [14], given the 'abundant' nature of their idempotents. Much has been done over the last few decades to explicate the structure and behaviour of abundant semigroups, and the subclass of adequate semigroups where idempotents commute and then type $A$ or ample semigroups (roughly akin to inverse semigroups). John also realised that the relations $\mathcal{R}^{*}$ and $\mathcal{L}^{*}$ were themselves contained in the larger relations, named $\widetilde{\mathcal{R}}$ and $\widetilde{\mathcal{L}}$, and perhaps semigroups for which each of these classes contain an idempotent would be interesting. This viewpoint has been confirmed time and again over the following decades. At a meeting of NBSAN in January 2017, Stuart Margolis announced they would be called Fountain Semigroups. These ideas influenced the early work of the second author, and later my own; I leave Mark to expand.

A side effect of the work on semigroups of quotients was the introduction of the study of endomorphism monoids of independence algebras ( $v^{*}$-algebras) [24]. We wanted to figure out a common framework to encompass the monoid (ring) of endomorphisms of a vector space and the full transformation monoid on a set. John and his student Lewin found results on products of idempotents generalising those for 
endomorphisms of vector spaces and self maps of sets. These ideas have been significantly developed and championed by João Araújo. In fact, an earlier article of John [16] shows that semigroups of square integer matrices are abundant, and every singular integer matrix is a product of idempotents. Much later, John and I put [16] into the framework of endomorphisms of stable basis algebras [21]; roughly speaking, these are to independence algebras what free modules over well-behaved domains are to vector spaces over their quotient rings. For John a highlight of the 1990s was his collaboration with Syd Bulman-Fleming [5], marrying ideas from the theory of acts to results on products of idempotents.

John's early vision has had lasting influence on my mathematics. For example, the work on acts threw up a number of finitary conditions for monoids, particularly that of coherency, that remains a topic of current research [25]. The work on quotients led to early collaborations with Pham Ngoc Ánh and László Márki, and then much later to an unexpected venture into commutative semigroup theory with Ánh, Márki and Pierre Grillet [1].

Early in the 1990s, John became one of the few people to realise, and certainly the first to act seriously upon this realisation, that ideas and techniques from infinite group theory and semigroup theory, together with notions from areas so far distant as automata and logic, should coalesce. This is well understood today but at the time it was revolutionary. John was the driving force behind a two-week NATO conference, held in York during August 1993 [17]. It is no exaggeration to say that this meeting was the catalyst in changing the perception of semigroup theory in the mathematical community; those that attended will never forget the experience.

\section{Mark V. Lawson}

It is to John that I owe my interest in semigroup theory. In the third year at the University of York, there were a range of modules to choose from and, since my main interest was in algebra, my choices were skewed heavily in that direction. John had taught us linear algebra and was known to be a clear expositor. Perhaps in part for this reason, two of the modules I chose were taught by John: one in logic and one in semigroup theory. Much as I did, and still do, find logic interesting, it was the semigroup theory which really caught my imagination. John is an exceptionally clear thinker and this comes across in his lectures and lecture notes. What is also significant, I think, is that John had a strong background in classical ring theory stemming from his time in Leeds. I did not know, of course, that John was becoming known for his semigroup research. But, looking back, I now realise that all these different elements combined to produce an exceptional module.

I became John's Ph.D. student in 1982, at the same time as my co-author. John's approach to supervising was to point me in the right direction, suggest some problems and patiently answer a truly unreasonable number of questions and objections from me. My starting point were four papers John had written [11-14] where he had introduced the class of so-called abundant semigroups as natural generalisations of regular semigroups. The motivation came from ring theory. As Vicky has pointed out, in the development of the algebraic theory of semigroups, ring theory has acted as a model. 
But this makes it sound too easy. In fact, it is so easy that a lot of people have been led astray. You may well prove a theorem for semigroups analogous to one for rings but it does not follow that it will have any merit. One of John's many insights about mathematical research was the need to find the right generalisation. This is evident in his work on semigroups of quotients. The key insight is that semigroup structure is more delicate than ring structure. For example, I knew, probably on the basis of reading [36], that for the multiplicative monoids of (regular) rings the following properties were equivalent: being orthodox, being inverse, being a union of groups and being a semilattice of groups. In other words, Chapters IV, V and VI of [26] collapse. Reading through the references to [30], I am reminded of something else: the very rapid development of regular semigroup theory at that time. John pointed me in the direction of papers by McAlister, Meakin, Nambooripad, Pastijn and Schein, to name just a few. This was an intellectually exciting time with each new paper revealing some hitherto unexpected feature of regular semigroups. I was particularly in awe of Nambooripad $[38,39]$ who with his theory of bi-ordered sets appeared to be a mathematical magician.

Let me conclude by saying something about how my subsequent research owes a big debt to John and my time as a graduate student at York. The goal of my thesis was to generalise some results from regular semigroup theory to suitable classes of abundant semigroups. This proved to be very difficult unless conditions were placed on the abundant semigroup to make them look more regular. On the other hand, John's paper [14] showed that proving deep theorems about abundant semigroups was possible. His construction could be viewed as something like a Rees matrix semigroup over a category and it was this that led me to think about the place of categories in semigroup theory; not in the sense of large categories of structures but rather as small categories viewed as being algebraic structures in their own right. This way of using categories in semigroup theory was certainly in the air at that time. In my thesis, I cite the preprint of the paper [41] and I had become aware of Ehresmann's work on ordered groupoids via the work of Nambooripad [38] and that of my fellow Ph.D. student Sheena Armstrong [3]. This set the scene for much of my later research in which this use of categories has played an essential rôle: the exploration of the impact of Ehresmann's work on inverse semigroup theory, summarised in my book [33]; putting abundant semigroups in a wider context that includes what are now called restriction semigroups [31]; the Morita equivalence of semigroups [35] which grew out of the work of Sunil Talwar [42], one of John's later Ph.D. students; non-commutative Stone duality [34] and the connections between inverse semigroups and topological groupoids; and the work [29] which connects topological categories and restriction semigroups.

\section{Scotland, Lisbon and beyond}

In 1976 there was a small conference in St Andrews, followed in 1977 by the British Mathematical Colloquium in Edinburgh. On these occasions, John met Don McAlister, Al Clifford, Peter Jones, Don Miller, Douglas Munn and Ulrich Knauer, and came away enthused. The first Oberwolfach meeting on semigroups was in 1978, when John had a long discussion during a hike in the snow with László Márki on how one 
might extend parts of the structure theory of regular semigroups to larger classes; this was the beginning of the contacts between the York and Budapest schools in semigroup theory, based on common interest in this topic. The Oberwolfach meeting also led to a collaboration with Batbedat on what we would now call left restriction semigroups [4]. These early mathematical acquaintances and friendships, many of which were established in Scotland and facilitated by Howie, had a deep influence on the protagonists. By the early 1980s, Howie and Tom Blyth were organising regular Semigroup Symposia in St Andrews. In 1982, John met Howie's then Ph.D. student, Gracinda Gomes - as did the two authors of this article - at one such meeting in St Andrews. John acted as Gracinda's external examiner in 1985 and in the following year Gracinda organised a semigroup conference in Lisbon to which John was invited. This was the first of his many visits to Lisbon to work with Gracinda and profoundly influenced the development of abstract algebra in Lisbon. John and Gracinda had a long and successful collaboration working on abundant, more particularly, type A (now called ample) semigroups, establishing results that show just how analogous their behaviour is to inverse semigroups [18]. Rather later, Gracinda invited the first author to visit, and yet later, Mária Szendrei; it was in this way that the word was spread concerning (left) type A and restriction semigroups. John, Gracinda and the first author later showed that free restriction semigroups (which coincide with free ample semigroups) embed into free inverse semigroups in a very natural way [19] (we did not expect this at the time). This was perhaps a catalyst for the work of another of John's students, Mark Kambites, who determined the structure of free (left) adequate semigroups using labelled bi-rooted trees (a kind of blown-up version of Munn trees) [28].

In the late 1980s John was fascinated by work of Jean-Eric Pin and Stuart Margolis and this led to him answering a question that they had left open [15]: namely, that every $E$-dense monoid has an $E$-dense $E$-unitary cover. This involved a beautiful insight in constructing covers, which was used in other contexts by both John and others. In particular, after a month in Paris, John, Pin and Pascal Weil produced a monster paper on covers [23], which has not been surpassed in the area.

A new direction late in (mathematical) life was reflection monoids. David Easdown and Tim Lavers wrote a paper on inverse braid monoids corresponding to braid groups. Artin groups generalise braid groups and have proven to be hugely important. John thought it should be possible to define and study Artin (inverse) monoids. Brent Everitt eventually persuaded John to start with reflection monoids [6,7].

A couple of years ago, Ben Steinberg produced a new proof of the Krohn-Rhodes theorem. John decided to give a final series of lectures on this material, allowing the first author and her own students to listen to the master once more.

\section{Coda}

We have tried to convey something of John's character in talking about his mathematics, although none of this quite captures his true essence. Simply put: he is universally 
admired and respected in semigroup circles and loved by his students and collaborators.

Open Access This article is distributed under the terms of the Creative Commons Attribution 4.0 International License (http://creativecommons.org/licenses/by/4.0/), which permits unrestricted use, distribution, and reproduction in any medium, provided you give appropriate credit to the original author(s) and the source, provide a link to the Creative Commons license, and indicate if changes were made.

\section{References}

1. Ánh, P.N., Gould, V., Grillet, P., Márki, L.: Commutative orders revisited. Semigroup Forum 89, 336-366 (2014)

2. Arbib, A., Krohn, K., Rhodes, J.: Algebraic Theory of Machines, Languages, and Semigroups. Academic Press, New York (1968)

3. Armstrong, S.: The structure of concordant semigroups, D.Phil. thesis, University of York (1985)

4. Batbedat, A., Fountain, J.: Connections between left adequate semigroups and $\gamma$-semigroups. Semigroup Forum 22, 59-65 (1981)

5. Bulman-Fleming, S., Fountain, J.: Products of idempotent endomorphisms of free acts of infinite rank. Monatsh. Math. 124, 1-16 (1997)

6. Everitt, B., Fountain, J.: Partial symmetry, reflection monoids and Coxeter groups. Adv. Math. 223, 1782-1814 (2010)

7. Everitt, B., Fountain, J.: Partial mirror symmetry, lattice presentations and algebraic monoids. Proc. Lond. Math. Soc. 107(3), 414-450 (2013)

8. Folley K (ed.): Semigroups: Proceedings of a Symposium on Semigroups, Wayne State University, Detroit, Michigan, 1968. Academic Press, New York (1969)

9. Fountain, J.: Completely right injective semigroups. Proc. Lond. Math. Soc. (3) 28, $28-44$ (1974)

10. Fountain, J.: Perfect semigroups. Proc. Edinb. Math. Soc. (2) 20, 87-93 (1976)

11. Fountain, J.B.: Right PP monoids with central idempotents. Semigroup Forum 13, 229-237 (1977)

12. Fountain, J.B.: A class of right PP monoids. Q. J. Math. 28, 285-300 (1977)

13. Fountain, J.B.: Adequate semigroups. Proc. Edinb. Math. Soc. 22, 113-125 (1979)

14. Fountain, J.B.: Abundant semigroups. Proc. Lond. Math. Soc. 44, 103-129 (1982)

15. Fountain, J.: E-unitary dense covers of E-dense monoids. Bull. Lond. Math. Soc. 22, 353-358 (1990)

16. Fountain, J.: Products of idempotent integer matrices. Math. Proc. Camb. Philos. Soc. 110, 431-441 (1991)

17. Fountain, J. (ed.): Semigroups, formal languages and groups, Proceedings of the NATO Advanced Study Institute, University of York, York, August 7-21, 1993, NATO Advanced Science Institutes Series C: Mathematical and Physical Sciences, vol. 466. Kluwer Academic Publishers Group, Dordrecht (1995). ISBN 0-7923-3540-6

18. Fountain, J., Gomes, G.M.S.: The Szendrei expansion of a semigroup. Mathematika 37, 251-260 (1990)

19. Fountain, J., Gomes, G.M.S., Gould, V.: The free ample monoid. Int. J. Algebra Comput. 19, 527-554 (2009)

20. Fountain, J., Gould, V.: Orders in rings without identity. Commun. Algebra 18, 3085-3110 (1990)

21. Fountain, J., Gould, V.: Relatively free algebras with weak exchange properties. J. Aust. Math. Soc. 75, 355-384 (2003)

22. Fountain, J., Petrich, M.: Completely 0-simple semigroups of quotients. J. Algebra 101, 365-402 (1986)

23. Fountain, J., Pin, J.-E., Weil, P.: Covers for monoids. J. Algebra 271, 529-586 (2004)

24. Gould, V.: Independence algebras. Algebra Universalis 33, 294-318 (1995)

25. Gould, V., Hartmann, M.: Coherency, free inverse monoids and related free algebras. Math. Proc. Camb. Phil. Soc. 163, 23-45 (2017)

26. Howie, J.M.: An Introduction to Semigroup Theory. Academic Press, London (1976)

27. Isbell, J.R.: Perfect monoids. Semigroup Forum 2, 95-118 (1971)

28. Kambites, M.: Free adequate semigroups. J. Aust. Math. Soc. 91, 365-390 (2011) 
29. Kudryavtseva, G., Lawson, M. V.: A perspective on non-commutative frame theory (2014). arXiv: 1404.6516

30. Lawson, M.V.: The structure theory of abundant semigroups. D.Phil. thesis, University of York (1985)

31. Lawson, M.V.: Semigroups and ordered categories I: the reduced case. J. Algebra 141, 422-462 (1991)

32. Lawson, M. V.: Rees matrix semigroups over cancellative categories, U.C.N.W Maths Preprint 91.27. University of Wales, Bangor

33. Lawson, M.V.: Inverse Semigroups: The Theory of Partial Symmetries. World Scientific, Singapore (1998)

34. Lawson, M.V.: A non-commutative generalization of Stone duality. J. Aust. Math. Soc. 88, 385-404 (2010)

35. Lawson, M.V.: Morita theory for semigroups with local units. J. Pure Appl. Algebra 215, 455-470 (2011)

36. McAlister, D.B.: Rees matrix covers for regular semigroups. J. Algebra 89, 264-279 (1984)

37. Munn, W.D.: Some recent results on the structure of inverse semigroups. In Folley K (ed.) Semigroups: Proceedings of a Symposium, Wayne State University, Detroit, Michigan, 1968, pp. 107-123. Academic Press, New York (1969)

38. Nambooripad, K.S.S.: The structure of regular semigroups. Memoirs of the American Mathematical Society 22 No. 224, (1979)

39. Nambooripad, K.S.S.: The natural partial order on a regular semigroup. Proc. Edinb. Math. Soc. 23, 249-260 (1980)

40. Rhodes, J.: Algebraic theory of finite semigroups. Structure numbers and structure theorems for finite semigroups. In Folley K (ed.) Semigroups: Proceedings of a Symposium on Semigroups, Wayne State University, Detroit, Michigan, 1968, pp. 125-162 (1969)

41. Rhodes, J.: On the cantor-dedekind property of the Tilson order on categories and graphs. J. Pure Appl. Algebra 48, 55-82 (1987)

42. Talwar, S.: Strong Morita equivalence and a generalisation of the Rees theorem. J. Algebra 181, 371394 (1996)

Publisher's Note Springer Nature remains neutral with regard to jurisdictional claims in published maps and institutional affiliations. 